\section{Pregnancy restores the regenerative capacity of the aged liver via activation of an mTORC1-controlled hyperplasia/hypertrophy switch}

Yuval Gielchinsky, ${ }^{1,2}$ Neri Laufer, ${ }^{2}$ Efi Weitman, ${ }^{3}$ Rinat Abramovitch, ${ }^{4}$ Zvi Granot, ${ }^{1}$ Yehudit Bergman, ${ }^{1,6}$ and Eli Pikarsky ${ }^{3,5}$

${ }^{1}$ Department of Developmental Biology and Cancer Research, Institute for Medical Research Israel-Canada, Hebrew University Hadassah Medical School, Ein Kerem, Jerusalem 91120, Israel; ${ }^{2}$ Department of Obstetrics and Gynecology, Hadassah-Hebrew University Medical Center, Jerusalem 91120, Israel; ${ }^{3}$ Department of Pathology and the Lautenberg Center for Immunology, Institute for Medical Research Israel-Canada, Hebrew University Hadassah Medical School, Ein Kerem, Jerusalem 91120, Israel; ${ }^{4}$ The Goldyne Savad Institute for Gene Therapy, Hadassah-Hebrew University Medical Center, Jerusalem 91120, Israel

Regenerative capacity is progressively lost with age. Here we show that pregnancy markedly improved liver regeneration in aged mice concomitantly with inducing a switch from proliferation-based liver regeneration to a regenerative process mediated by cell growth. We found that the key mediator of this switch was the Akt/mTORC1 pathway; its inhibition blocked hypertrophy, while increasing proliferation. Moreover, pharmacological activation of this pathway sufficed to induce the hypertrophy module, mimicking pregnancy. This treatment dramatically improved hepatic regenerative capacity and survival of old mice. Thus, cell growth-mediated mass reconstitution, which is relatively resistant to the detrimental effects of aging, is employed in a physiological situation and holds potential as a therapeutic strategy for ameliorating age-related functional deterioration.

Supplemental material is available at http://www.genesdev.org.

Received October 21, 2009; revised version accepted January $25,2010$.

In aging organisms, tissue regenerative capacity declines and healing in response to injury is delayed (Labat-Robert 2004; Kirkwood 2005; Beausejour and Campisi 2006; Rossi et al. 2008; Schumacher et al. 2008). This effectwhich is observed in liver, skin, bone, hematopoietic system, blood vessels, nerve, and muscle-is attributable to the altered functions of many biological processes (Kirkwood 2005; Beausejour and Campisi 2006). These

[Keywords: Liver regeneration; aging; hypertrophy; hyperplasia; mTORC1] Corresponding authors.

${ }^{5}$ E-MAIL peli@hadassah.org.il; FAX 972-2-6426268.

${ }^{6}$ E-MAIL Yehudit.Bergman@huji.ac.il; FAX 972-2-6414583.

Article is online at http://www.genesdev.org/cgi/doi/10.1101/gad.563110. include changes in growth factors or in extracellular matrix components, accumulation of DNA damage, increased presence of intracellular oxygen-reactive species, and decline in responsiveness of progenitor cells (LabatRobert 2004; Rossi et al. 2008; Schumacher et al. 2008). Liver regeneration, a process that rapidly compensates for the acute loss of liver parenchyma in patients with liver tumors or fulminant hepatitis (Michalopoulos 2007), is widely used as a model of tissue regeneration and surgical stress, a major problem in the geriatric population. Studies have shown that, in old mice, the liver regenerates significantly more slowly than in young mice (Iakova et al. 2003; Timchenko et al. 2006). This effect is already seen in 1-yr-old rats (Bucher et al. 1964) and mice (Supplemental Fig. S1). This decline has therapeutic relevance, as surgical resection is often the best option in patients with primary or secondary hepatic malignancies (Asiyanbola et al. 2008). However, given the considerable increase (by $2 \%$ per year) (Asiyanbola et al. 2008) in the odds ratio for mortality in the aged population, devising ways to improve liver regeneration in older patients is of paramount clinical importance.

\section{Results and Discussion}

It was shown recently that heterochronic parabiosis (connecting the circulations of a young and an old mouse) can restore the regenerative capacity of striated muscle in old mice and increase the basic rate of cell proliferation in aged livers (Conboy et al. 2005). The effect of heterochronic parabiosis on liver regeneration was not studied. Pregnancy can be viewed as a natural state akin to parabiosis, where organisms partly share blood systems-in this case, an adult organism (the pregnant mother) is exposed to extremely young organisms (the fetuses). Pregnancy in mice increases baseline proliferation of pancreatic $\beta$ cells and neurons and enhances post-injury remyelination (Shingo et al. 2003; Gregg et al. 2007; Karnik et al. 2007). We therefore set out to examine whether pregnancy also attenuates the age-related decline in regenerative capacity of the liver. Using serial magnetic resonance imaging (MRI), which accurately measures liver volume (Inderbitzin et al. 2004; Ben Moshe et al. 2007), we analyzed the process of liver regeneration after two-thirds partial hepatectomy in nonpregnant and near-term pregnant 3-mo-old (hereafter "young") and 10- to 12-mo-old ("aged") mice. This procedure, which has been shown before to accurately measure liver volume (Inderbitzin et al. 2004; Ben Moshe et al. 2007), allowed us to follow single mice along the regeneration process. In the nonpregnant groups, $2 \mathrm{~d}$ after surgery, the total liver volume (mean \pm SEM) regenerated to $82 \% \pm 8 \%$ of the original size in young mice, while in aged mice, the liver regenerated to only $46 \%$. In contrast, liver regeneration in aged pregnant mice was dramatically more efficient, with $96 \% \pm 3 \%$ of the liver volume restored within $2 \mathrm{~d}$ (Fig. 1A-C). In the aged mice, blood coagulation (indicative of the liver's synthetic capacity) was pathological in the nonpregnant group, but within normal limits in the pregnant group (Supplemental Fig. S2a). Similarly, whereas aged nonpregnant mice were lethargic after surgery, their pregnant counterparts were relatively active (Supplemental Fig. S2b). Post-hepatectomy 
A
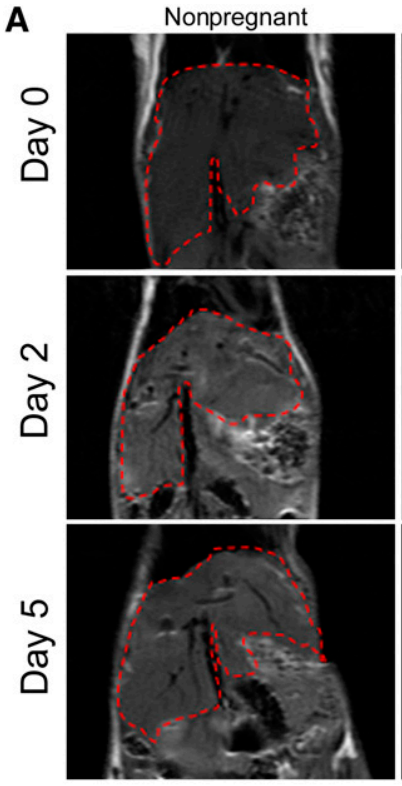

B

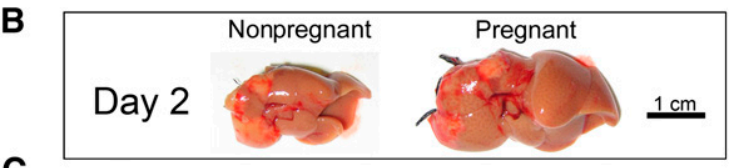

C

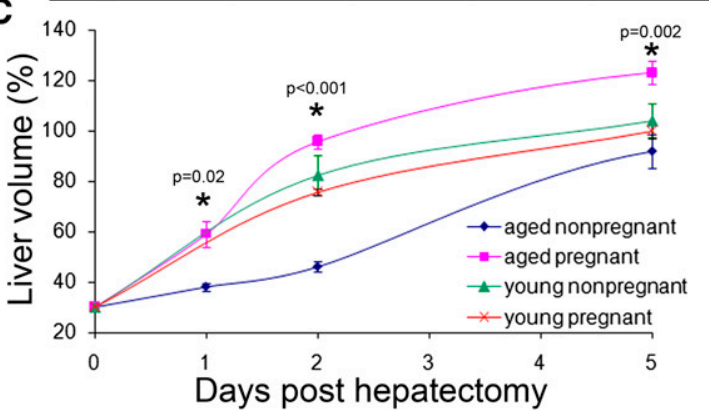

Figure 1. Pregnancy improves liver regeneration in aged mice. $(A)$ Representative serial MRI images of individual aged mice on the indicated days after two-thirds partial hepatectomy. Red hatched lines denote the liver contours. Bar, $1 \mathrm{~cm}$. $(B)$ Photographs of representative livers of aged mice removed $2 \mathrm{~d}$ after surgery. $(C)$ For each mouse, liver volume on days $0,1,2$, and 5 was determined by MRI and was recorded as a percentage of the liver volume prior to partial hepatectomy (mean \pm SEM). $\left({ }^{*}\right) P$-values were calculated for aged pregnant mice $(n=5)$ relative to aged nonpregnant mice $(n=5)$ using Student's $t$-test. (Aged) 10-12 mo old; (young) 3 mo old.

mortality in aged mice declined from $47 \%$ (nine out of 19 ) in the nonpregnant group to $9 \%$ (two out of $22 ; P=0.003$, Fisher's exact test) in the pregnant group (Fig. 4E). Thus, in the aged mice, the rate of liver volume gain, liver function, and, most importantly, survival after partial hepatectomy were all markedly improved by pregnancy.

Liver regeneration normally begins with a priming phase, which is followed by a spurt of regeneration during which most of the hepatocytes enter the cell cycle (Taub 2004; Michalopoulos 2007). We postulated that pregnancy in aged mice enhances liver regeneration by shortening the priming phase or by recruiting a larger number of hepatocytes into the cell cycle. To test this hypothesis, we injected nonpregnant and pregnant mice with the thymidine analog 5-bromo-2-deoxyuridine
(BrdU) at several time points after partial hepatectomy and assayed its incorporation into hepatocytes using immunohistochemistry. As expected, brisk proliferation occurred in the nonpregnant group between 48 and $96 \mathrm{~h}$ post-hepatectomy (Fig. 2A). Surprisingly, in the pregnant group, hardly any BrdU-labeled hepatocytes were observed at any of the time points measured. To rule out the possibility that we missed a specific time point at which hepatocytes in pregnant mice enter the $S$ phase, we administered BrdU in the drinking water from the time of partial hepatectomy until $4 \mathrm{~d}$ after the surgical procedure, when the mice were killed. This would ensure that any hepatocytes entering the S phase during that 4-d period would be labeled with BrdU. This analysis also showed that very few hepatocytes in the pregnant mice had incorporated $\mathrm{BrdU} 16 \% \pm 4 \%$ in the pregnant mice compared with $83 \% \pm 7 \%$ in the nonpregnant mice; $P=0.002$, Student's $t$-test) (Fig. 2B). Pregnancy also affected liver regeneration in young mice, in which BrdU incorporation rates of $92 \% \pm 1 \%$ and $5 \% \pm 1 \%$ were recorded in the nonpregnant and pregnant groups, respectively $(P<0.0001$, Students's $t$-test $)$. To rule out the possibility that pregnancy influenced BrdU labeling, small bowel samples were immunostained together with liver specimens on the same slide. Unlike liver sections, small bowel cells were clearly BrdU-labeled to the same extent, indicating that differential BrdU incorporation or metabolism cannot explain the observed differences (Supplemental Fig. S3).

We therefore postulated that the restored capacity of the aged liver for regeneration in aged pregnant mice is a function of cell growth rather than cell proliferation. Indeed, while in nonpregnant aged mice a 13\% increase in the average hepatocyte cross-sectional area was observed after partial hepatectomy, in pregnant aged mice this increase was $66 \%$ (Fig. 2C-E). Both FACS and "hepatocrit" analyses of hepatectomized aged mice confirmed that hepatocytes isolated from the pregnant group were larger than those from the nonpregnant group (Supplemental Fig. S4). Comparing the extent of proliferation and hypertrophy of nonpregnant, mid-pregnant, and late pregnant mice showed that the hypertrophy module gradually takes dominance during pregnancy (Table 1). To study the fate of the hypertrophied hepatocytes, we subjected aged, late pregnant mice to partial hepatectomy, and this time administered BrdU in the drinking water only after delivery, $5 \mathrm{~d}$ after partial hepatectomy. Control mice were nonhepatectomized aged pregnant mice. Interestingly, after delivery, the hypertrophic hepatocytes that are generated in pregnant hepatectomized mice undergo considerable proliferative activity (Supplemental Fig. S5). This suggests that pregnancy-related hypertrophy is maintained by a substance that is modulated continuously during pregnancy (either up-regulated or downregulated), yet returns to the nonpregnant levels after delivery. We immunostained liver sections for the cell cycle regulators $\mathrm{p} 53, \mathrm{p} 21$, and $\mathrm{p} 27$. This analysis indicated that, whereas levels of p27 did not differ between nonpregnant and pregnant mice (data not shown), both p53 and p21 are up-regulated after hepatectomy in nonpregnant mice but not in pregnant mice. This suggests that the up-regulation of these cell cycle inhibitors occurs in response to hepatocyte proliferation, and thus is absent from the pregnant mice (Supplemental Fig. S6). Taken together, these findings indicate that, during pregnancy, 

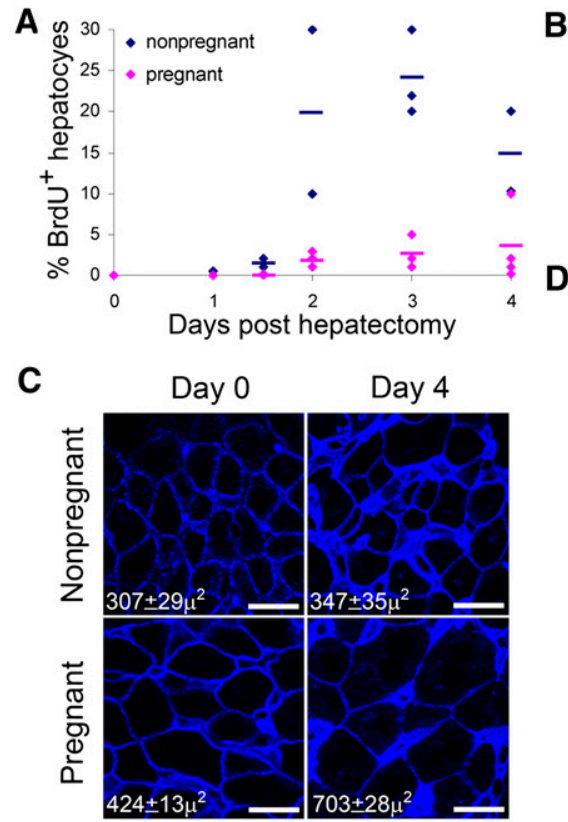

E

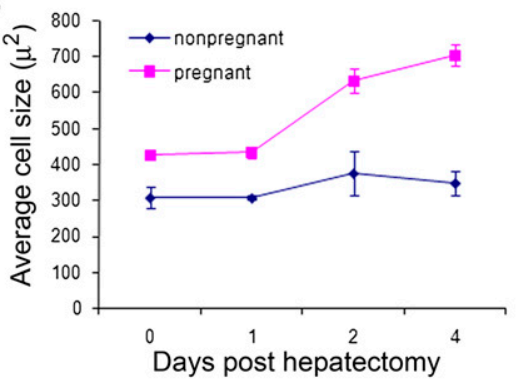

$B$

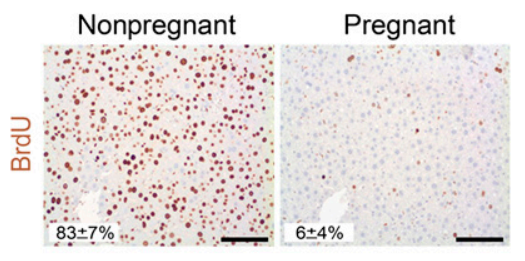

을
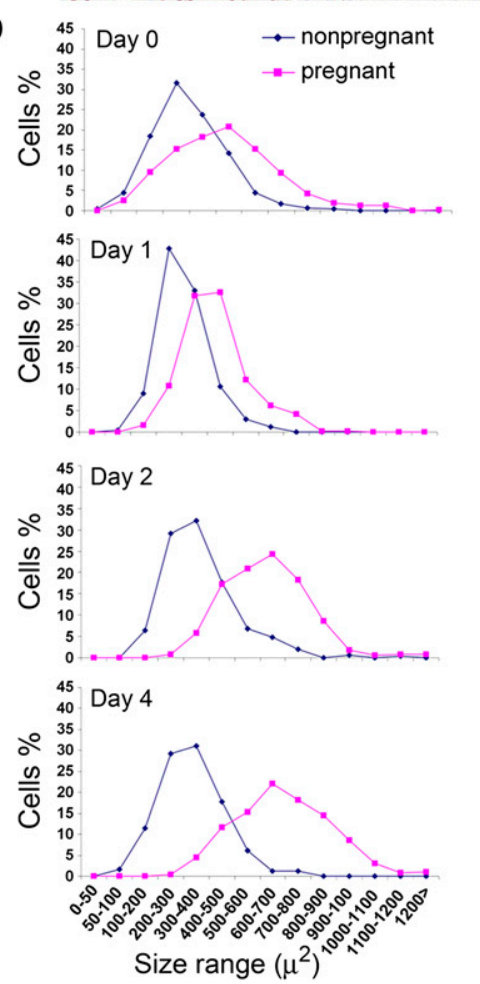

Figure 2. Liver regeneration in pregnancy proceeds via the hypertrophy module. $(A)$ Percentage of BrdU-positive cells on the indicated days after two-thirds partial hepatectomy in aged mice. Nonpregnant and pregnant mice were injected with BrdU at the indicated time points after partial hepatectomy. BrdU incorporation into hepatocytes was assayed using immunohistochemistry. Each data point represents a single mouse of the indicated groups; horizontal lines represent the average value for each group. $P<0.05$, nonparametric linear regression. $(B)$ Immunohistochemical staining for BrdU in aged mice. To rule out the possibility that a specific time point at which hepatocytes in pregnant mice enter the $\mathrm{S}$ phase was missed, BrdU was administered in the drinking water from the time of partial hepatectomy until $4 \mathrm{~d}$ after the surgical procedure, when the mice were sacrificed. Bars, $100 \mu \mathrm{m} . P=0.002$, Student's $t$-test. $(C)$ Representative E-cadherin-stained images demonstrating changes in cell size. Bars, $20 \mu \mathrm{m}$. $(D)$ Cell size distribution in the livers of aged nonpregnant (blue) and pregnant (pink) mice on the indicated days after surgery. Each data point represents two or three mice. For each mouse, four fields were counted, harboring a total of at least 100 cells. (E) Average cell size in livers of aged nonpregnant (blue) and pregnant (pink) mice on the indicated days after surgery (mean \pm SEM). $P=0.0001$, Mann-Whitney test.

hypertrophy, rather than proliferation, is the main mechanism by which the liver regains its volume and function.

What is the source of the hypertrophy-inducing factor? To distinguish the putative roles of circulating maternal hormones from other physiological signals emanating directly from the embryo or in response to implantation, we mated young females with vasectomized males, which results in pseudopregnancy-a transient alteration of maternal pituitary and ovarian steroid hormones that mimics the changes during the first half of normal gestation (Erskine 1998). A similar decrease in post-hepatectomy proliferation and increase in cell size were noted in the pseudopregnant and midpregnant mice compared with the nonpregnant mice, albeit smaller than the effect of late pregnancy (Table 1). These results suggest that at least part of the effect of pregnancy on liver regeneration can be attributed to maternally derived factors. Taken together, the above findings confirmed that, in aged pregnant mice, post-hepatectomy liver regeneration results largely from hepatocyte hypertrophy. Slight liver growth as a function of hypertrophy was shown to occur in pregnancy (Kennedy et al. 1958; Hollister et al. 1987). Restoration of liver mass after partial hepatectomy was shown to occur in several situations, such as after treatment with dexamethasone or 5 -fluorouracil (Nagy et al. 2001), in deficiency of STAT3 (Haga et al. 2005) or Skp2 (Minamishima et al. 2002), and after $\gamma$-irradiation (Michalopoulos and DeFrances 1997), indicating that hyperplasia and hypertrophy are two alternative modules for liver regeneration. Our results provide novel evidence that a physiological condition-i.e., pregnancycauses a switch from proliferation-based liver regeneration to a regeneration process mediated by cell growth.

The Akt/mTORC1 pathway is a key mediator of cell growth in many cellular systems (Manning and Cantley 2007), including that of the liver (Mullany et al. 2007; Haga et al. 2009). We therefore examined whether pregnancy influences components of this pathway. Western immunoblotting of liver extracts revealed that, on post-hepatectomy days 1,2 , and 4, phosphorylation of Akt, S6 kinase, and 4E-BP1 were markedly increased in pregnant but not in nonpregnant mice (Fig. 3A; Supplemental Fig. S7). Earlier (6 h after hepatectomy), Akt phosphorylation was increased in both groups, but was higher in the pregnant mice (data not shown). The

Table 1. Effect of pregnancy on hepatocyte proliferation and hypertrophy after partial hepatectomy

\begin{tabular}{lcccc}
\hline & Nonpregnant & Mid-pregnant & Late pregnant & Pseudopregnant \\
\hline Percent BrdU incorporation & $92 \% \pm 1 \%$ & $60 \% \pm 6 \%$ & $5 \% \pm 1 \%$ & $59 \% \pm 10 \%$ \\
Cell size (square microns) & $258 \pm 2$ & $346 \pm 3$ & $663 \pm 31$ & $348 \pm 3$ \\
\hline
\end{tabular}

Partial hepatectomy was performed at day 5 post-coitum mice (mid-pregnant and pseudopregnant) or days 12-14 post-coitum mice (late pregnant), or on virgin young female mice that received continuous BrdU since operation. Mice were sacrificed $4 \mathrm{~d}$ after surgery, and percent BrdU incorporation and cell size were assessed. 


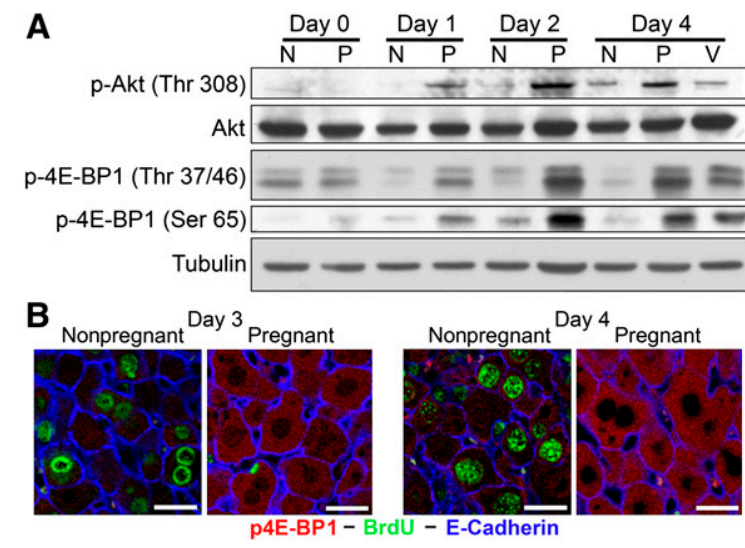

Figure 3. The Akt/mTORCl pathway mediates the hypertrophy module in regenerating livers of pregnant mice. $(A)$ Western blot analyses of liver extracts from aged nonpregnant $(\mathrm{N})$ and aged pregnant $(\mathrm{P})$ mice at the indicated times after two-thirds partial hepatectomy; $(\mathrm{v})=$ Liver extracts from young mice treated with the PTEN inhibitor bpV(phen). (B) Representative images of livers from aged nonpregnant (top panels) and aged pregnant (bottom panels) mice harvested on days 3 and 4 after surgery and subjected to triple immunofluorescence staining for phospho-4E-BP1 (red), BrdU (green), and E-cadherin (blue). Bars, $20 \mu \mathrm{m}$.

above findings were confirmed by costaining for BrdU and phospho-4E-BP1 (Fig. 3B). To assess the functional significance of Akt/mTORCl signaling for liver regeneration in pregnant mice, we treated mice with the mTORC1 inhibitor rapamycin. This treatment resulted in a significant increase in the hepatocyte proliferation rate in pregnant mice $(25 \% \pm 8 \%$ compared with $2 \% \pm 1 \%$; $P=$ 0.04 , Student's $t$-test) (Fig. 4A), concomitantly with elimination of pregnancy-induced cell growth (Fig. 4B). These findings differ markedly from numerous in vitro and in vivo systems demonstrating a strong anti-proliferative response evoked by rapamycin in other situations (Sanders et al. 2008). These results suggest that the Akt/mTORC1 pathway is a key determinant of hepatocyte hypertrophy in regenerating livers of pregnant mice.

Can this switch in the liver regeneration module from hyperplasia to hypertrophy explain the observed improvement in the regenerative capacity of aged pregnant mice? If so, tilting the balance toward hypertrophy should improve liver regenerative capacity in old nonpregnant mice as well. We postulated that activation of the Akt/mTORC1 pathway in such mice might suffice to favor the hypertrophy pathway. To test this hypothesis, we first treated young nonpregnant mice with the phosphatase and tensin homolog (PTEN) inhibitor bisperoxovanadium 1,10-phenanthroline $[\mathrm{bpV}(\mathrm{phen})]$ before subjecting them to partial hepatectomy. Western blot analysis of phosphorylated Akt and 4E-BP1 confirmed that bpV(phen) treatment activates the Akt/mTORC1 pathway (Fig. 3A). Immunohistochemical analysis disclosed that liver regeneration in the $\mathrm{bpV}(\mathrm{phen})$-treated mice proceeds via hypertrophy, as indicated by the low proliferation index and growth of $115 \%$ in the mean cross-sectional area (Fig. 4C; Supplemental Fig. S8), indicating that bpV(phen) treatment of nonpregnant young mice suffices to activate the hypertrophy regeneration module. To support the possibility that the effect of $\mathrm{bpV}$ (phen) is mediated via mTORC1 signaling, we compared post-hepatectomy proliferation rates in control mice, mice treated with
bpV(phen) alone, rapamycine alone, or combined treatment with $b p V($ phen) and rapamycine. Whereas rapamycin treatment alone reduced post-hepatectomy proliferation rate (Sanders et al. 2008), the $b p V(p h e n)-i n d u c e d$ switch from hyperplasia to hypertropy was clearly blocked by rapamycin treatment (Fig. 4D). Haga et al. (2009) have shown recently that genetic activation of Akt via PDK1 contributes to liver regeneration by regulating cell size, further supporting the possibility that the $\mathrm{bpV}(\mathrm{phen})$ effect is mediated via Akt activation. This enabled us to test our hypothesis that this module may restore the regenerative capacity in old mice. To determine whether activation of the hypertrophy module by $b p V(p h e n)$ is sufficient to restore the liver's regenerative capacity in old mice, we subjected female mice aged 18-24 mo to partial hepatectomy without (control) or with $\mathrm{bpV}$ (phen) treatment. Post-hepatectomy blood coagulation and locomotor activity tests confirmed that bpV(phen) treatment resulted in a significant improvement in recovery from partial hepatectomy compared with nontreated old mice (Fig. 4E; Supplemental Fig. S2). Remarkably, the mortality rate in the $\mathrm{bpV}$ (phen)-treated old mice was zero out of nine, compared with four out of nine in the control group $(P=0.014$, Fisher's exact test $)$ (Fig. 4E).

Organ and limb regeneration have fascinated humankind from the earliest days of science. In mammalians, accurate regeneration of an entire limb or organ does not occur. Instead, regenerative programs have evolved that result in reconstitution of organ function and mass, but do not accurately replace anatomy and cellular composition. Liver regeneration after partial hepatectomy is perhaps the best-studied mammalian model for such processes. In this model, the liver mass and function, but not its micro- and macroanatomy, are usually regenerated via proliferation of terminally differentiated hepatocytes. This study demonstrates two physiological modules for reconstitution of liver mass: hyperplasia (the primary module in nonpregnant mice) and hypertrophy (the primary module in pregnant mice). The latter module is activated in pregnant mice via signaling through the Akt/mTORC1 pathway (Fig. 4F). The evolutionary advantage of the hypertrophy module in pregnancy is not clear. It is possible that hepatocyte hypertrophy is preferred over hepatocyte proliferation in transient situations like pregnancy, where there is a time-limited demand for increasing liver function; when acute loss of liver mass is encountered at the same time, the hypertrophy module is the default one. In any case, it seems that the choice of regenerative module is critical for expression of the negative manifestations of aging. The hyperplasia module is negatively affected by aging, which delays restoration of liver function in old mice and results in a decrease in their ability to accommodate acute loss of liver mass. This may be due to accumulating damaged nuclei, resulting in a reduction in the pool of hepatocytes that can be recruited rapidly to the cycling pool. Our findings show that the hypertrophy regeneration module is less affected by aging; pharmacological activation of Akt in old organisms induces the hypertrophy module, thereby restoring the functional capacity for liver regeneration. Thus, our results suggest that a useful therapeutic approach to improve liver regeneration in the aged might involve activation of a regenerative module that is less sensitive to aging. 
A

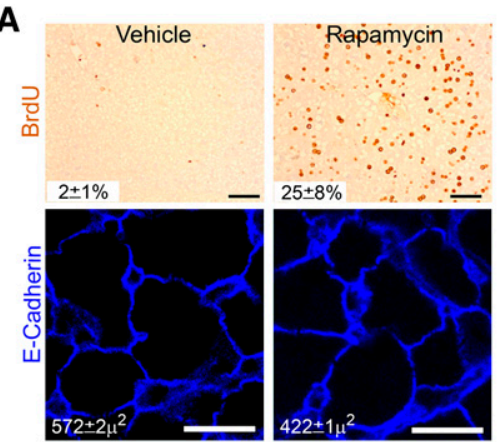

C

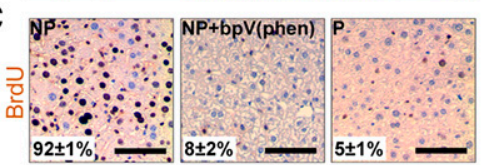

E

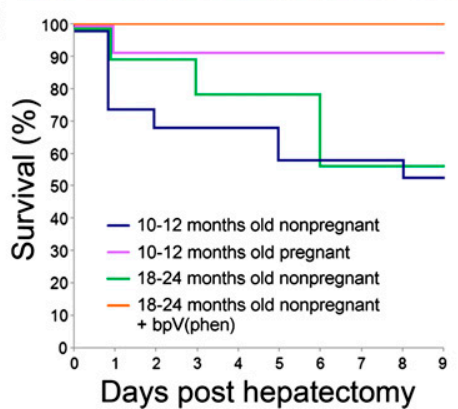

B

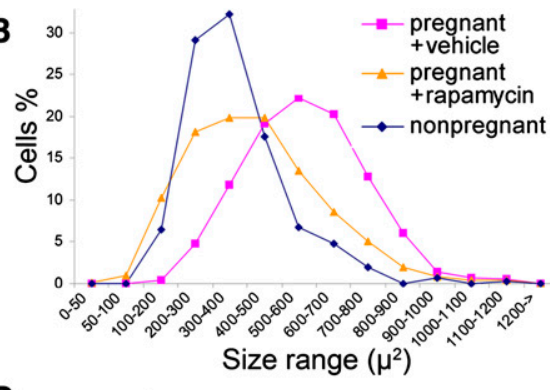

D rapamaycin bpV(phen)

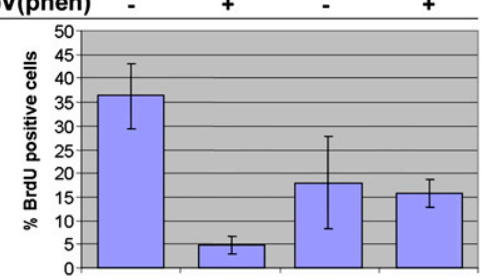

$\mathbf{F}$

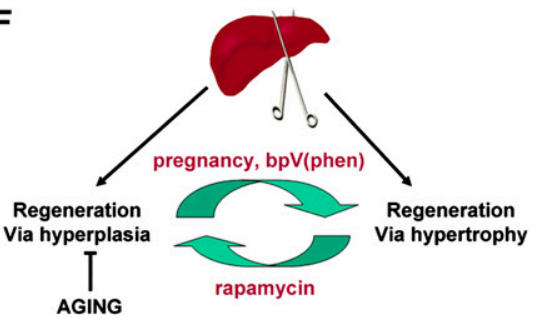

Figure 4. The Akt/mTOR pathway controls the switch from the hyperplasia to the hypertrophy regeneration module. (A, top panel) Immunohistochemical staining for BrdU in vehicle- and rapamycin-treated aged pregnant mice $2 \mathrm{~d}$ after partial hepatectomy. Note the apparently paradoxical proliferation induced by the anti-proliferative drug rapamycin in the aged pregnant mice. Bars, $100 \mu \mathrm{m} . P=0.04$, Student's $t$-test. (Bottom panel) Immunofluorescence staining for E-cadherin (blue). Bars, $20 \mu \mathrm{m}$. (B) Cell size distribution $2 \mathrm{~d}$ after surgery in hepatectomized livers of aged pregnant vehicle-treated (pink), aged pregnant rapamycin-treated (orange), and aged nonpregnant untreated (blue) mice. Each data point is representative of at least three mice. $(C)$ Immunohistochemical staining for $\mathrm{BrdU}$ of livers from young nonpregnant (NP), nonpregnant treated with $\mathrm{bpV}(\mathrm{phen})$ [NP + $\mathrm{bpV}(\mathrm{phen})]$ or pregnant $(\mathrm{P})$ mice $4 \mathrm{~d}$ after partial hepatectomy and continuous BrdU administration. Bars, $100 \mu \mathrm{m}$. $(D)$ Average proliferation indices $2 \mathrm{~d}$ after hepatectomy with continuous BrdU in drinking water in mice of the indicated treatment groups. $(E)$ KaplanMeier plots depicting survival in aged pregnant (pink), aged nonpregnant (blue), old (green), and $\mathrm{bpV}(\mathrm{phen})$-treated old (orange) mice. (F) Proposed model for the two modules of liver regeneration. In most situations, liver regeneration occurs via hyperplasia. Certain circumstances, such as pregnancy and pharmaceutical activation of the Akt $/ \mathrm{mTORCl}$ pathway [e.g., by treatment with $\mathrm{bpV(phen)],} \mathrm{favor} \mathrm{the} \mathrm{hypertrophy} \mathrm{module.} \mathrm{Aging} \mathrm{affects} \mathrm{the}$ latter module much less strongly than it affects the hyperplasia module, where it results in impairment of liver function and significant mortality.

\section{Materials and methods}

\section{Animal studies}

All animal experiments were performed in accordance with the guidelines of the Institutional Committee for the Use of Animals for Research. The genetic background of all mice was C57 Black. Pseudopregnancy was induced by mating females with vasectomized males and observing for the presence of vaginal plugs. For rapamycin treatment, mice were injected intraperitoneally (i.p.) for three consecutive days with rapamycin $(0.2 \mathrm{mg} / \mathrm{kg}$ body weight diluted in DMSO; LC Laboratories), starting $3 \mathrm{~h}$ before the hepatectomy. For PTEN inhibition, bpV(phen) $(3.3 \mu \mathrm{g} / \mathrm{g}$ body weight diluted in normal saline; Alexis Biochemicals) was administered i.p. on the day before hepatectomy and once a day for $3 \mathrm{~d}$ thereafter. Locomotor activity was monitored using a photocell cage, $43.2 \mathrm{~cm} \times 43.2 \mathrm{~cm}$ (Med Associates), with 16 beam I/R arrays located along each wall of the box. Data are mean values of the total numbers of beam breaks (representing horizontal activity).

\section{Measurement of cell size}

Sections ( $5 \mu \mathrm{m}$ thick) were prepared from formalinfixed, paraffin-embedded livers. Slides were stained with anti-E-cadherin antibodies. Digital images were obtained using a Nikon 90i confocal microscope at $400 \times$ magnification. The numbers of pixels in 100-300 individual hepatocytes for each mouse were scored with Image (NIH) by an observer who was blinded to the treatment group.

\section{Statistics}

All values are means \pm SEM. The indicated statistical tests were performed using StatXact software. Where applicable, all tests were two-sided.

Methods for MRI, Western blot, immunohistochemistry, and immunofluorescence analyses, as well as further data on animal studies, reagents, and antibodies used can be found in the Supplemental Material.

\section{Acknowledgments}

We are grateful to Nathalie Corchia, Shafika Alkawasmy, Moran Ephrayim, Eti Avraham, and Naama Kanarek for technical assistance; Dr. Rami Yaka for help with the open-field recordings; Dr. Ifat Uzi for advice with animal care; and Avigail Dreazen for help with confocal imaging. We thank Shirley Smith for editorial assistance, and Drs. Ittai Ben-Porath, Yosefa Avraham, Roni Seger, Yuval Dor, and Oded Meyuhas for discussions and critical reading of the manuscript. We are also indebted to Dr. Norman Grover for help with statistical evaluations. This work was supported by grants from the Israel Science Foundation (Y.B. and E.P.), the National Institutes of Health (Y.B.), the Israel Cancer Research Fund (Y.B. and E.P.), the Hadassah Women's Health Fund (Y.G. and Y.B.), and the Dr. Miriam and Sheldon G. Adelson Medical Research Foundation (E.P.). R.A. is supported by the Horwitz Foundation through The Center for Complexity Science. Y.G. is a participant in the Hadassah physician scientist program.

\section{References}

Asiyanbola B, Chang D, Gleisner AL, Nathan $\mathrm{H}$, Choti MA, Schulick RD, Pawlik TM. 2008. Operative mortality after hepatic resection: Are literature-based rates broadly applicable? J Gastrointest Surg 12: 842-851.

Beausejour CM, Campisi J. 2006. Ageing: Balancing regeneration and cancer. Nature 443: 404-405.

Ben Moshe T, Barash H, Kang TB, Kim JC, Kovalenko A, Gross E, Schuchmann M, Abramovitch R, Galun E, Wallach D. 2007. Role of caspase- 8 in hepatocyte response to infection and injury in mice. Hepatology 45: 1014-1024.

Bucher NL, Swaffield MN, Ditroia JF. 1964. The influence of age upon the incorporation of thymidine-2-C14 into the DNA of regenerating rat liver. Cancer Res 24: 509-512.

Conboy IM, Conboy MJ, Wagers AJ, Girma ER, Weissman IL, Rando TA. 2005. Rejuvenation of aged progenitor cells by exposure to a young systemic environment. Nature 433: 760-764.

Erskine MS. 1998. Pseudopregnancy. In Encyclopedia of reproduction (ed. E Knobil, JD Neill), pp. 120-124. Academic Press, San Diego, CA.

Gregg C, Shikar V, Larsen P, Mak G, Chojnacki A, Yong VW, Weiss S. 2007. White matter plasticity and enhanced remyelination in the maternal CNS. J Neurosci 27: 1812-1823.

Haga S, Ogawa W, Inoue H, Terui K, Ogino T, Igarashi R, Takeda K, Akira S, Enosawa S, Furukawa H, et al. 2005. Compensatory recovery of 


\section{Gielchinsky et al.}

liver mass by Akt-mediated hepatocellular hypertrophy in liverspecific STAT3-deficient mice. J Hepatol 43: 799-807.

Haga S, Ozaki M, Inoue H, Okamoto Y, Ogawa W, Takeda K, Akira S, Todo S. 2009. The survival pathways phosphatidylinositol-3 kinase (PI3-K)/phosphoinositide-dependent protein kinase 1 (PDK1)/Akt modulate liver regeneration through hepatocyte size rather than proliferation. Hepatology 49: 204-214.

Hollister A, Okubara P, Watson JG, Chaykin S. 1987. Reproduction in mice: Liver enlargement in mice during pregnancy and lactation. Life Sci 40: 11-18.

Iakova P, Awad SS, Timchenko NA. 2003. Aging reduces proliferative capacities of liver by switching pathways of $\mathrm{C} / \mathrm{EBP} \alpha$ growth arrest. Cell 113: 495-506.

Inderbitzin D, Gass M, Beldi G, Ayouni E, Nordin A, Sidler D, Gloor B, Candinas D, Stoupis C. 2004. Magnetic resonance imaging provides accurate and precise volume determination of the regenerating mouse liver. J Gastrointest Surg 8: 806-811.

Karnik SK, Chen H, McLean GW, Heit JJ, Gu X, Zhang AY, Fontaine M, Yen MH, Kim SK. 2007. Menin controls growth of pancreatic $\beta$-cells in pregnant mice and promotes gestational diabetes mellitus. Science 318: 806-809.

Kennedy GC, Pearce WM, Parrott DM. 1958. Liver growth in the lactating rat. I Endocrinol 17: 158-160.

Kirkwood TB. 2005. Understanding the odd science of aging. Cell 120: 437-447.

Labat-Robert J. 2004. Cell-matrix interactions in aging: Role of receptors and matricryptins. Ageing Res Rev 3: 233-247.

Manning BD, Cantley LC. 2007. AKT/PKB signaling: Navigating downstream. Cell 129: 1261-1274.

Michalopoulos GK. 2007. Liver regeneration. J Cell Physiol 213: 286-300.

Michalopoulos GK, DeFrances MC. 1997. Liver regeneration. Science 276: 60-66.

Minamishima YA, Nakayama K, Nakayama K. 2002. Recovery of liver mass without proliferation of hepatocytes after partial hepatectomy in Skp2-deficient mice. Cancer Res 62: 995-999.

Mullany LK, Nelsen CJ, Hanse EA, Goggin MM, Anttila CK, Peterson M, Bitterman PB, Raghavan A, Crary GS, Albrecht JH. 2007. Aktmediated liver growth promotes induction of cyclin $\mathrm{E}$ through a novel translational mechanism and a p21-mediated cell cycle arrest. J Biol Chem 282: 21244-21252.

Nagy P, Teramoto T, Factor VM, Sanchez A, Schnur J, Paku S, Thorgeirsson SS. 2001. Reconstitution of liver mass via cellular hypertrophy in the rat. Hepatology 33: 339-345.

Rossi DJ, Jamieson CH, Weissman IL. 2008. Stems cells and the pathways to aging and cancer. Cell 132: 681-696.

Sanders JA, Lakhani A, Phornphutkul C, Wu KY, Gruppuso PA. 2008. The effect of rapamycin on DNA synthesis in multiple tissues from late gestation fetal and postnatal rats. Am I Physiol Cell Physiol 295: C406-C413. doi: 10.1152/ajpcell.00450.2007.

Schumacher B, Garinis GA, Hoeijmakers JH. 2008. Age to survive: DNA damage and aging. Trends Genet 24: 77-85.

Shingo T, Gregg C, Enwere E, Fujikawa H, Hassam R, Geary C, Cross JC, Weiss S. 2003. Pregnancy-stimulated neurogenesis in the adult female forebrain mediated by prolactin. Science 299: 117-120.

Taub R. 2004. Liver regeneration: From myth to mechanism. Nat Rev Mol Cell Biol 5: 836-847.

Timchenko LT, Salisbury E, Wang GL, Nguyen H, Albrecht JH, Hershey JW, Timchenko NA. 2006. Age-specific CUGBP1-eIF2 complex increases translation of CCAAT/enhancer-binding protein $\beta$ in old liver. I Biol Chem 281: 32806-32819. 


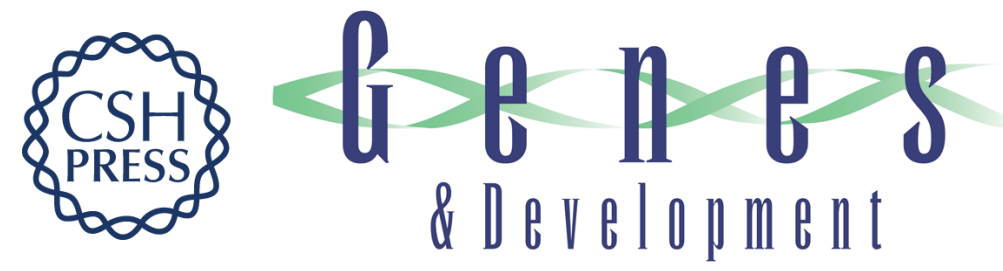

\section{Pregnancy restores the regenerative capacity of the aged liver via activation of an mTORC1-controlled hyperplasia/hypertrophy switch}

Yuval Gielchinsky, Neri Laufer, Efi Weitman, et al.

Genes Dev. 2010, 24:

Access the most recent version at doi:10.1101/gad.563110

\section{Supplemental http://genesdev.cshlp.org/content/suppl/2010/03/11/24.6.543.DC1 \\ Material}

Related Content Regeneration Switch

Annalisa M. VanHook

Sci. Signal. March , 2010 3: ec88

References This article cites 27 articles, 9 of which can be accessed free at:

http://genesdev.cshlp.org/content/24/6/543.full.html\#ref-list-1

Articles cited in:

http://genesdev.cshlp.org/content/24/6/543.full.html\#related-urls

\section{License}

Email Alerting

Service

Receive free email alerts when new articles cite this article - sign up in the box at the top right corner of the article or click here.

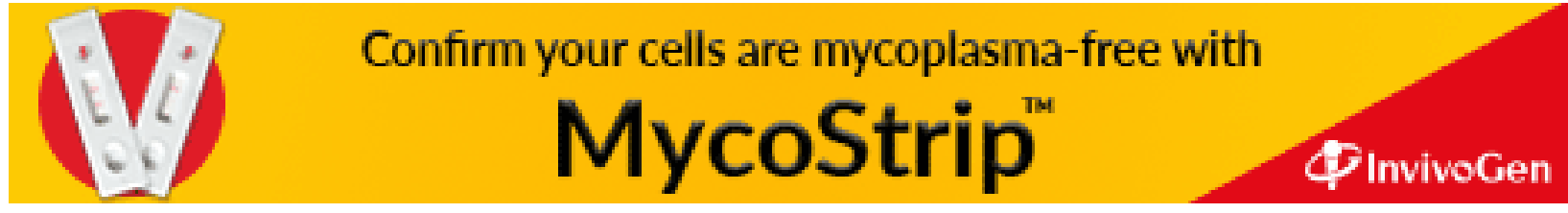

